\title{
RUANG SENI DAN KULINER JALANAN DI SENEN
}

\author{
Andrean Hermanto ${ }^{1)}$, Suwandi Supatra ${ }^{21}$ \\ 1) Program Studi S1 Arsitektur, Fakultas Teknik, Universitas Tarumanagara, andreanhermanto@live.com \\ 2) Program Studi S1 Arsitektur, Fakultas Teknik, Universitas Tarumanagara, ybhan50@gmail.com
}

\begin{abstract}
Abstrak
Seiring berkembangnya Urbanisasi, masalah yang terkait, khususnya yang berdampak pada hubungan masyarakat, menjadi 'topik hangat' dalam pengembangan proyek berbasis "Third Place". Tergerusnya komunitas dan wadahnya sering dengan perkembangan urbanisasi yang diidentifikasi sebagai Segregasi Sosial menjadi sebuah masalah yang menarik untuk dibahas oleh para sosiolog. Fokus isu yang diangkat dalam proyek ini adalah "Bagaimana menciptakan "Third Place" di kawasan Senen'. Lokasi proyek berada di Kawasan Senen tepatnya di Jl. Stasiun Senen, Jakarta Pusat yang merupakan salah satu pusat perbelanjaan di jakarta. Lokasi tapak berada di antara pusat komersil, perumahan, dan sarana transportasi dengan mobilitas pedestrian yang tinggi. Tujuan dari proyek ini adalah menciptakan sebuah "Third Place" yang menjadi penghubung diantara rumah dan kantor dimana warga Senen dapat datang dan menghabiskan waktu luang mereka, serta memberikan fasilitas yang dibutuhkan oleh kota, terutama disekitar tapak proyek sebagai penghubung antara moda transportasi publik (terminal dan stasiun) dengan fasilitas kawasan serta mengembalikan citra kawasan senen yang merupakan daerah yang kental dengan kesenian dan makanan. Metode penelitian yang dilakukan dalam proyek ini dimulai dengan menemukan fasilitas / program yang dibutuhkan oleh masyarakat sekitar tapak,yang juga bertujuan untuk menyelesaikan masalah dari kawasan tersebut. kemudian dilanjutkan dengan mengidentifikasi, danmemunculkan kembali / merestorasi ciri khas kawasan yang hilang (dalam kasus ini adalah kesenian), lalu dilanjutkan dengan proses mendesain fasilitas yang akan menghasilkan besaran dan organisasi ruang dalam proyek ini.
\end{abstract}

\section{Kata kunci: kuliner; senen; seni; third place}

\begin{abstract}
As Urbanization blooms, related problems, especially those that affect community relations, become a 'hot topic' in developing projects based on 'Third Place'. The erosion of the community and its community often with the development of urbanization identified as Social Segregation becomes an interesting problem to be discussed by sociologists. The focus of the issue raised in this project is "How to create a Third Place in Senen area." The location of the project is in the Senen, precisely on JI. Stasiun Senen, Jakarta Pusat which is one of the popular shopping centers in Jakarta. The site was located between commercial centers, housing, and transportation facilities with high pedestrian mobility. The purpose of this project is to create a "Third Place" which is a link between homes and offices where residents of Senen can come and spend their free time, and provide the facilities needed by the city, especially around the project site as a link between public transportation modes (Senen terminal and Senen station) with regional facilities and restore the image of the senen area which is an area that is thick with arts and food. The research methodology carried out in this project began by finding the facilities / programs needed by the community around the site, which also aims to resolve problems in the area. then proceed with identifying, and bringing back / restoring the characteristics that lost in this area (in this case, art), then proceed with the process of designing a facility that will produce the area and organization of space in this project.
\end{abstract}

\section{Keywords: Senen; street art; street food; third place}




\section{PENDAHULUAN}

\section{Latar Belakang}

Mulai dari kedai kopi, tempat potong rambut pinggir jalan, hingga pos ronda dalam komplekkomplek berperan menjadi "Third Place" dalam kehidupan bermasyarakat kita sehari-hari. Namun apakah makna dari "Third Place" tersebut? Ray Oldenburg seorang sosiolog melakukan penelitian tentang "tempat-tempat" penting dalam kehidupan bermasyarakat dan menemukan satu gagasan besar: manusia memiliki 3 Tempat dalam hidup mereka "The Three Places".

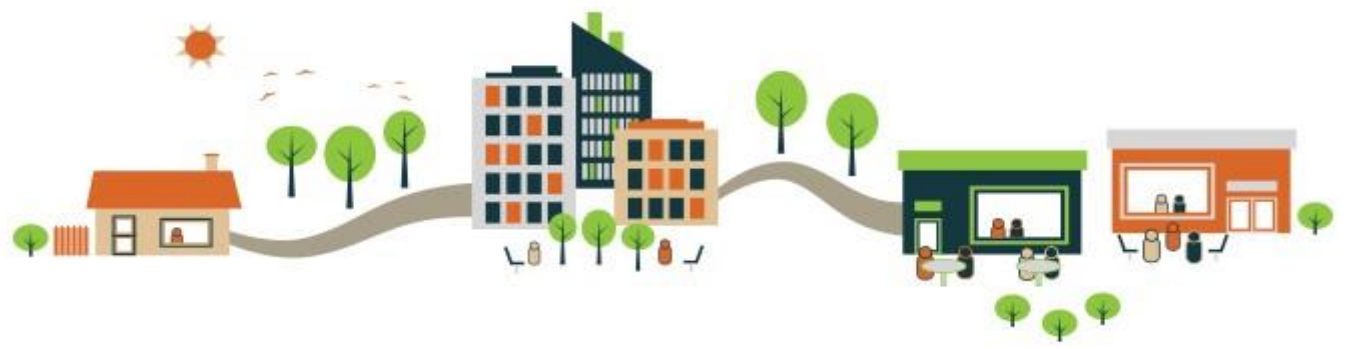

Gambar 1. The "Three Places" yang dideskripsikan Ray Oldenburg Sumber: https://medium.com/@Bisner/how-to-engage-your-community-b2f960e2df21

Pembagian ruang selalu menjadi masalah dalam perencanaan sebuah kota. Pilihan memisahkan fungsi (bekerja, hidup, bergerak, menghibur) atau kombinasi dari mereka pada satu tempat adalah salah satu variabel utama proyek perkotaan. Berkembangnya ruang coworking, makerspace, dll. melalui kegiatan budaya atau artistik membawa 'warna' baru untuk perdebatan ini. "Third Place" adalah Ruang Tidak sepenuhnya publik atau sepenuhnya pribadi, ruang ini adalah ruang menengah yang kita sebut sebagai "Third Place". "Third Place" adalah istilah yang diciptakan oleh sosiolog Ray Oldenburg yang mengacu pada tempat di mana orang menghabiskan waktu antara rumah (First Place) dan bekerja (Second Place). Perencana urban berusaha menstabilkan lingkungan dengan berfokus pada peran penting yang dapat dimainkan oleh "Third Place" dalam memperkuat komunitas. Mereka adalah lokasi di mana kita bertukar ide, memiliki waktu yang baik, dan membangun hubungan dengan sesama.

\section{Rumusan Masalah}

Berangkat dari latar belakang pengembangan "Third Place" yang dikaitkan dengan permasalahan yang ada di masyarakat perkotaan yaitu segregasi sosial maka rumusan masalah yang dipaparkan adalah: Mengapa kawasan Senen, Jakarta Pusat terpilih sebagai lokasi tapak terpilih untuk mengadakan proyek "Third Place"?, dan Bagaimana caranya untuk dapat menyesuaikan program terpilih dengan tapak dan memenuhi kriteria sebagai "Third Place" ?.

\section{Tujuan Proyek}

1. Menghasilkan sebuah bangunan yang dapat menjadi "Third Place" bagi masyarakat daerah Senen, Jakarta Pusat.

2. Memberikan dampak bagi perkembangan Street Food dan Art serta popularitasnya

\section{Batasan Proyek}

Pembahasan dan perancangan ditujukan untuk daerah Jakarta Pusat, kelurahan Senen, kecamatan Senen dimana menjadi sasaran untuk dijadikan sebuah Street Food and Art Space dan disesuaikan dengan program kawasan sekitar tapak yaitu untuk melayani masyarakat yang tinggal dekat dengan tapak yang berada ditengah daerah Senen yang memiliki banyak pemukiman penduduk. Proyek ini mempunyai besaran tingkat pelayanan kecamatan. 


\section{KAJIAN LITERATUR}

\section{"Third Place"}

"The nature of a third place is one in which the presence of a "regular" is always welcome, although never required." - Ray Oldenberg

Ray Oldenburg, seorang sosiolog dalam bukunya "The Great Good Place" (1999) mengembangkan gagasan tentang "Third Place" dalam kehidupan kita: tempat berkumpul di luar lingkup tempat bekerja dan rumah bagi kelompok orang terhubung satu sama lain. Lokasi dapat bervariasi, tetapi tujuannya tetap sama: tempat untuk bersosialisasi dalam komunitas. Dalam teorinya Ray Oldenburg mengklasifikasikan 3 Ruang sosial dalam hidup manusia (The Three Places). Penelitian "Third Place" oleh Oldenburg didasarkan di sekitar ruang sosial utama yang ditempati orang: kantor dan rumah menjadi yang pertama dan kedua. Dimana pekerjaan adalah pengalaman sosial yang formal dan terstruktur, dan rumah adalah pengalaman pribadi, tempat ketiga adalah lingkungan yang lebih santai di mana orang merasa nyaman dan menikmati waktu untuk bersosialisasi, untuk bersantai, dan untuk menghabiskan waktu bersama orang di sekitar Mereka. Sebuah kelompok tetap adalah apa yang membuat tempat ketiga.

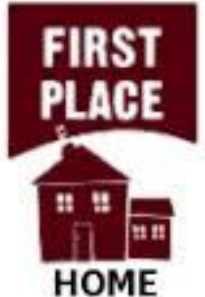

Gambar 2. The "Three Places" yang dideskripsikan Ray Oldenburg Sumber: https://www.feic.org/third-places/

"Third Place" yang baik dipenuhi oleh interaksi antar penggunanya dan menghasilkan hubungan spontan antara orang dari berbagai latar belakang sosial dan ekonomi yang diperlukan untuk membangun komunitas yang kuat, menciptakan empati antara orang, dan mempertahankan pandangan diri sebagai Bagian dari sesuatu yang lebih besar. Oldenburg melihat ruang-ruang ini semakin berkurang selama dekade terakhir dimana daerah perumahan, daerah pinggiran kotayang dimana dahulunya memiliki tempat berkumpul publik dan bersosialisasi bergerak menjadi lebih kompetitif dan swasta, mengurangi hubungan sosial antar warga.

Dalam satu atau lain hal, kita selalu memiliki "Third Place". "Third Place" dahulu hanyalah tempat di mana kita menghabiskan waktu ketika kita tidak di rumah dan tidak bekerja. Sekarang, tempat ketiga mengambil peran yang jauh lebih besar dalam hidup kita dan kemudian, dalam mendefinisikan tempat, "Third Place" tidak lagi hanya sekedar tempat rekreasi atau kegiatan santai; mereka telah menjadi bagian yang tergabung dalam gaya hidup kita secara keseluruhan. Dalam hal ini kita perlu mengenali bahwa, bagi beberapa orang, terutama di industri kreatif, memiliki wadah untuk mengekspresikan diri mereka sendiri ("Third Place") adalah sebuah aset yang beharga. "Third Place" juga memiliki konsep unik untuk sebuah tempat karena mereka dapat menyatukan lintas generasi melalui program mereka daripada karakteristik tempat lain, dalam kata lain "Third Place" berperan sebagai 'Ruang tamu' dalam sebuah Kawasan.

\section{Karakteristik dari "Third Place"}

Menurut Ray Oldenberg dalam bukunya "The Great Good Place" (1999) sebuah "Third place" harus memiliki karakteristik sebagai berikut: 


\section{Bersifat Netral}

Agar kota dan lingkungan dapat menawarkan interaksi yang kaya dan bervariasi, harus ada tanah yang di atasnya orang dapat berkumpul. Harus ada menjadi tempat di mana individu dapat datang dan pergi kapanpun mereka mau, di mana tidak diperlukan untuk menjadi tuan rumah, dan di mana semua merasa di rumah.

\section{"Leveller"}

Sebuah tempat yang menyamaratakan, oleh sifatnya, adalah tempat yang inklusif. Tempat ini dapat diakses oleh seluruh masyarakat umum tanpa terkecuali dan tidak menetapkan kriteria keanggotaan.

\section{Percakapan adalah aktivitas utama}

Percakapan bukan hanya merupakan daya tarik utama tetapi adalah "jiwa" dari "Third Place", Wajib dan harus ada dalam lingkarnya.

\section{Aksesibilitas dan akomodasi yang mudah}

Tempat ketiga yang menyajikan layanan terbaik adalah yang dimana sebuah individu maupun kelompok pada hampir semua waktu baik siang ataupun malam dapat datang dengan kepastian bahwa "Third Place" akan berada di sana.

\section{Memiliki langganan}

Apa yang menarik langganan ke "Third Place" tidak diberikan oleh manajemen tetapi oleh sesama pengunjung. Tempat ketiga hanyalah sekedar sebuah ruang kecuali mereka yang ada di sana membuatnya menjadi hidup, dan mereka adalah pelanggan tetap. Ini adalah pelanggan tetap yang memberikan tempat karakter dan yang menjamin bahwa pada setiap kunjungan tertentu beberapa geng akan berada di sana.

\section{"Low Profile"}

Sebagai struktur fisik, "Third Place" biasanya Polos. Salah satu alasan sulit untuk meyakinkan beberapa orang pentingnya "Third Place" adalah bahwa begitu banyak dari "Third Place" memiliki penampilan yang polos. Dalam budaya di mana iklan dan penampilan dihargai atas substansi dari tempat tersebut, adalah sebuah tantangan bagi arsitek dan interior desainer untuk mengubah cara pandang masyarakat terhadap "Third Place" terutama bagi yang belum tahu.

\section{Sebuah rumah yang jauh dari rumah}

Menggunakan definisi pertama, kedua, dan ketiga rumah (menurut Meriam - Webster), tempatketiga tidak tidak memenuhi syarat, nomor (1) "family's place of residence" atau (2) "social unit formed by a family living together." Tapi definisi ketiga dari rumah Sebagai menawarkan "a congenial environment" (lingkungan yang menyenangkan) lebih tepat Untuk berlaku untuk definisi "Third Place" dibandingkan rumah. Lingkaran keluarga mungkin dapat bertahan Tanpa memiliki lingkungan yang menyenangkan tetapi "Third Place" tidak bisa.

Karakter tempat ketiga ditentukan sebagian besar Semua oleh penggunjung tetap dan ditandai dengan menyenangkan suasana hati, yang kontras dengan orang yang lebih serius keterlibatan dalam bidang lain. Meskipun secara radikal berbagai jenis pengaturan dari rumah, ketiga tempat ini sangat mirip dengan rumah yang baik di kenyamanan psikologis dan dukungan mental. 


\section{Isu Utama: Segregasi sosial dalam masyarakat perkotaan}

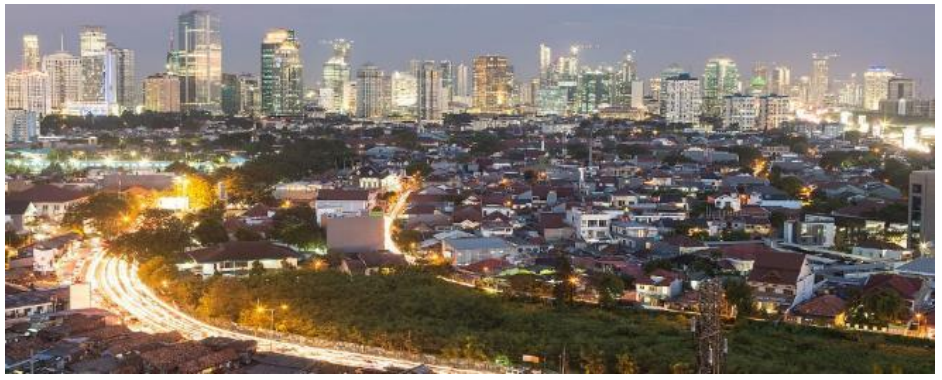

Gambar 3. Perbedaan kampong dan kompleks perumahan elit, bukti terjadinya segregasi Sumber: https://www.fes-indonesia.org/id/program/transformasi-sosial-di-perkotaan/

Era globalisasi mendorong mobilitas penduduk antar wilayah semakin tinggi, yang menurut Appadurai (1990) salah satunya dicirikan dengan mobilitas lintas budaya tanpa batas. Akibat dari mamaraknya urbanisasi yang ragam akan budaya dan juga ideologi, perbedaan agama dan ikatan emosional (suku) menjadikan kehidupan di kota menjadi heterogen. Bagi kalangan yang tidak dapat melakukan pluralisme sosial tentu akan mendapati berbagai persoalan ketika harus berinteraksi secara sosial. Yang terjadi adalah segregasi sebagai upaya pengelompokan sosial sesuai dengan kelasnya. Umumnya ikatan yang menjadikan segregasi sosial adalah suku, agama dan ideologi hingga kelas ekonomi. Salah satu bentuk segregasi modern adalah berkumpulnya para masyarakat ekonomi atas di perumahan elit dengan gaya hidup ekslusif.

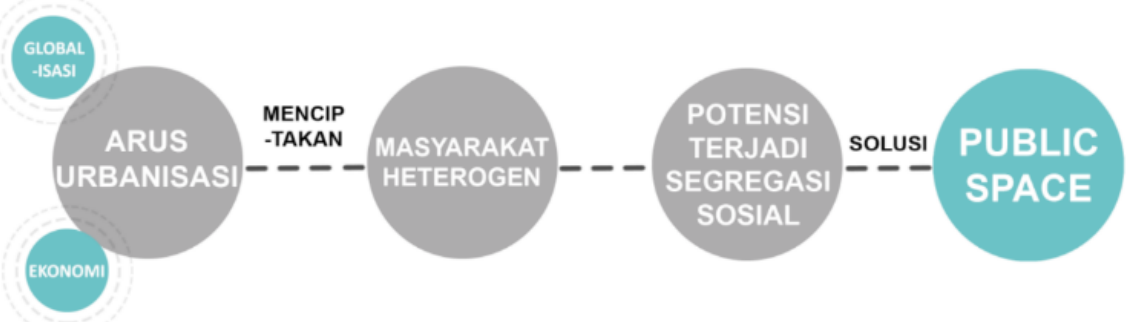

Gambar 4. Potensi segregasi sosial dari Urbanisasi Sumber: Penulis, 2019

Salah satu 'penawar' dari permasalahan ini adalah penciptaan sebuah ruang publik untuk semua. Publik adalah milik rakyat; untuk mereka semua. Bagi saya, definisi utama publik adalah jika semua orang, tanpa terkecuali kelas sosial, jenis kelamin, warna kulit, orientasi seksual, dapat menggunakan ruang yang sama. Dalam kasus mal atau pusat perbelanjaan tidak dapat mereka tidak dapat dianggap sebagai ruang publik pada intinya ini dikarenakan, meskipun terbuka untuk masyarakat, tidak semua orang dapat masuk dan dapat menggunakan fasilitas yang mall tawarkan sesuai dengan identitas mereka.

\section{Fenomena 'Street Food' dan Perkembangannya}

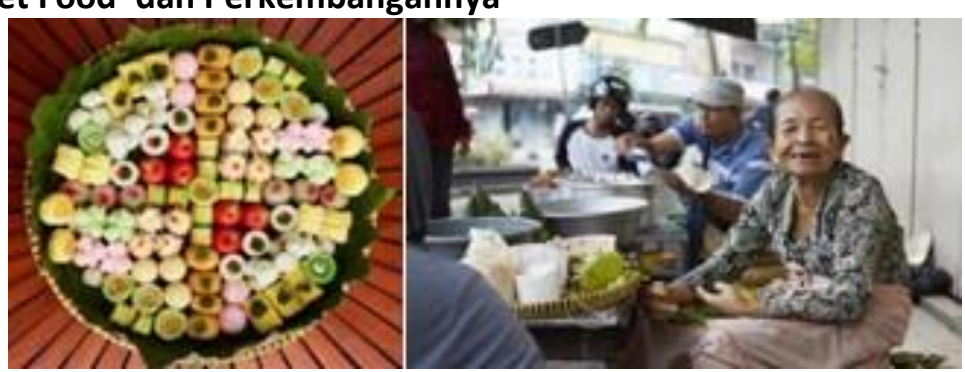

Gambar 5. Contoh Street Food dan Penjualnya

Sumber: https://food.detik.com/info-kuliner/d-4546134/legenda-jajan-pasar-yogyakarta-mbahsatinem-jadi-cerita-street-food-netflix 
Pertumbuhan populasi perkotaan telah menstimulasi peningkatan jumlah pedagang kaki lima di banyak kota-kota di seluruh dunia. Migrasi dari daerah pedesaan ke pusat kota telah menciptakan kebutuhan sehari-hari di antara banyak pekerja untuk makan di luar rumah. Hal tersebut menyebabkan permintaan akan makanan yang relatif murah dan siap saji meningkat karena orang, memiliki lebih sedikit waktu untuk menyiapkan makanan. Di beberapa bagian Eropa dan Amerika, 'Street Food', telah menjadi bagian integral dari budaya makanan lokal.

Istilah 'Street Food' menggambarkan berbagai macam makanan dan minuman siap saji yang dijual dan terkadang disiapkan di tempat-tempat umum, terutama jalanan. Seperti makanan cepat saji, persiapan akhir makanan jalanan terjadi ketika pelanggan memesan makanan di mana makanan tersebut dibeli atau dibawa pergi. Makanan jalanan terhitung lebih murah dibandingkan dengan makanan di restoran dan menawarkan alternatif yang menarik daripada makanan buatan rumah.

'Street Food' sering mencerminkan budaya lokal tradisional dan memiliki variasi yang tak ada habisnya. Ada banyak keanekaragaman dalam bahan baku serta dalam persiapan minuman makanan jalanan, makanan ringan dan makanan. Kios- kios penjual biasanya terletak di luar atau di bawah atap yang mudah diakses dari jalan. Mereka memiliki fasilitas tempat duduk yang terkadang bersifat alakadarnya.

\section{Fenomena 'Street Art' dan Perkembangannya}

Pengertian 'Street Art' secara umum adalah objek visual yang mengandung nilai seni yang dibuat dalam lokasi publik. Namun seni ini kerap menuai pelarangan terkait aksi mencoret-coret di tempat publik di banyak negara termasuk di Indonesia. Di Indonesia sendiri, 'Street Art' hanya identik dengan grafitti dan mural yang memuat seni dan terkadang disematkan sebuah pesan sosial. meskipun di beberapa negara lainnya nama 'Street Art' ini mencakup cabang-cabang seni lainnya seperti 'Street Sculpture', 'Street Art', dan 'Street Performer'.
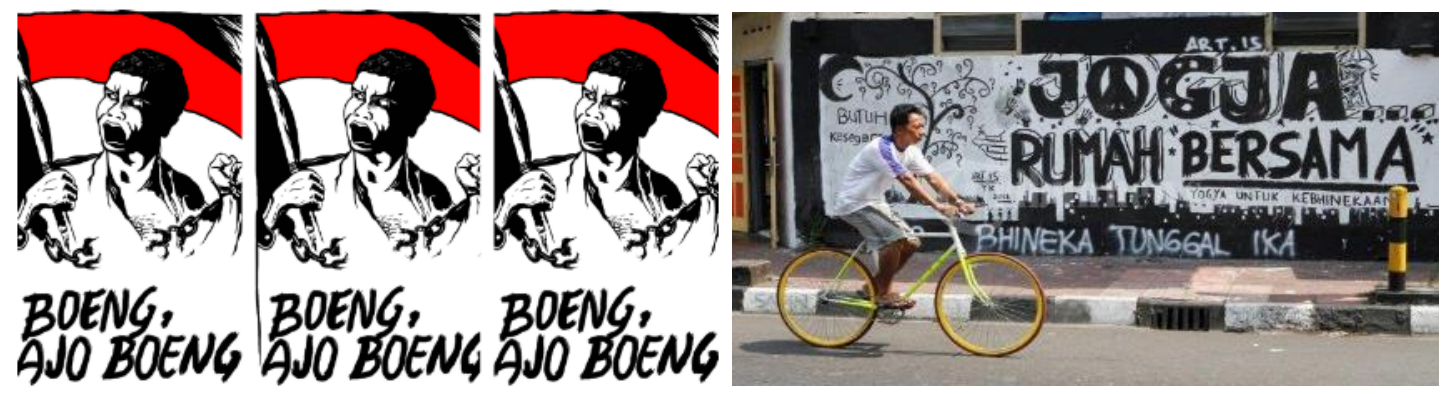

Gambar 6. Seni dalam Kehidupan Bermasyarakat

Sumber:https://id.wikipedia.org/wiki/Berkas:Boeng,_ajo,_Boeng!_karya_Affandi.jpg

Perkembangan 'Street Art' di Indonesia sudah dapat ditemui sejak jaman penjajahan dahulu salah satu contohnya adalah karya dari pelukis affandi. pada saat itu Bung Karno yang meminta tolong kepada Sudjojono seorang pelukis untuk membuat poster penyemangat perang kepada rakyat Indonesia. Deskripsi singkat pada lukisan poster, yang ditulis oleh Mia Bustam, istri Sudjojono menjelaskan, saat itu Sudjojono memberi mandat ke Affandi untuk membuat poster tersebut. Poster tersebut menggambarkan seorang pemuda membawa bendera Indonesia dengan semangat dan dibawahnya disematkan kalimat "Boeng Ajo Boeng". kalimat itu muncul ketika mereka sedang berdiskusi tentang judul poster, saat itu Chairil Anwar datang dan mengatakan bahwa di daerah pasar senen para wanita penghibur memanggil para pria dengan kata "Boeng Ajo Boeng". 


\section{METODE PERANCANGAN}

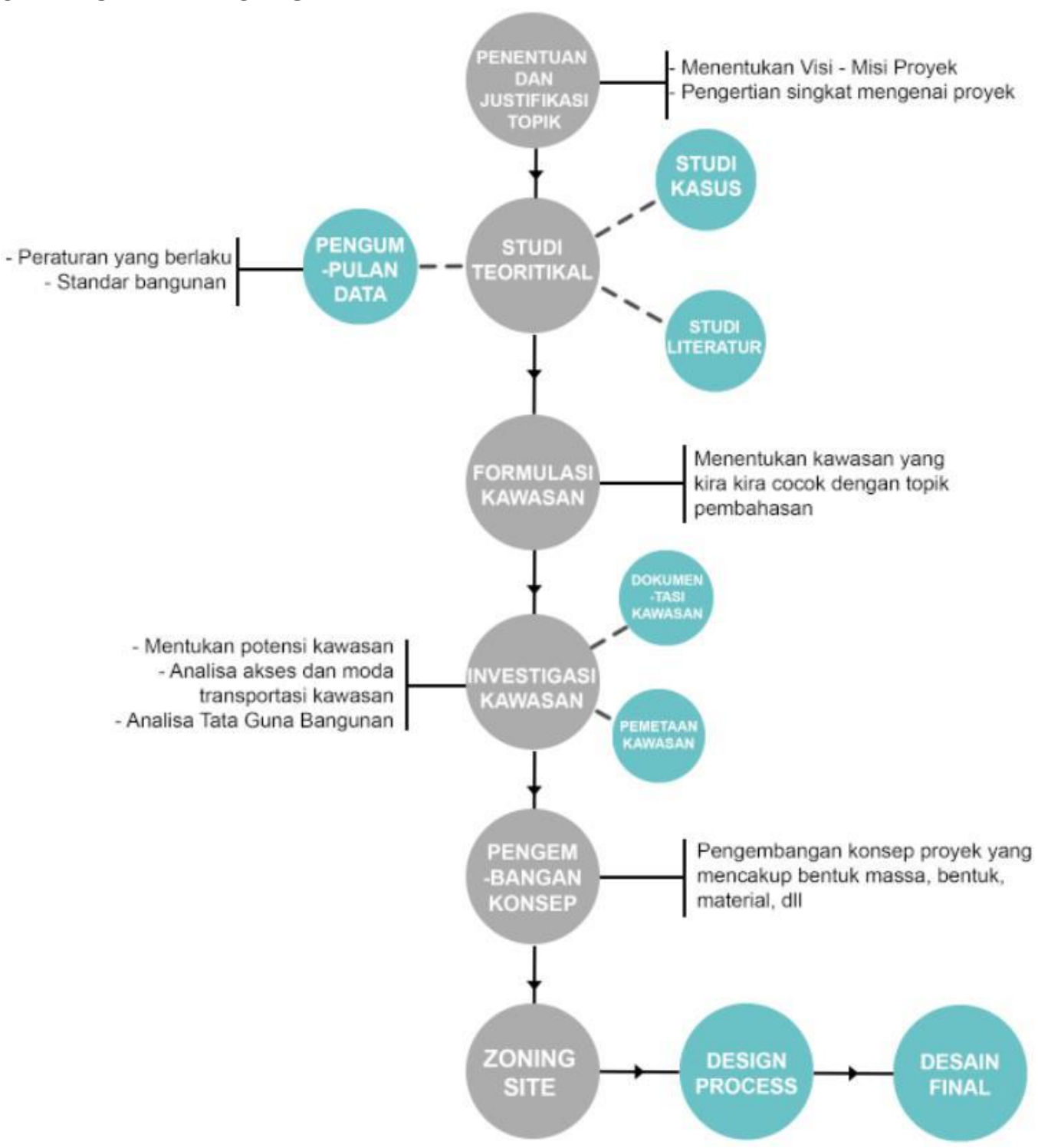

Gambar 7. Diagram Alur Metode Perancangan

Sumber: Penulis, 2019

Pengumpulan data primer dan data sekunder, digunakan metode yang akan dijelaskan sebagai berikut:

\section{Data Primer}

Merupakan data yang diperoleh melalui proses pengambilan data secara langsung pada lokasi, dengan cara sebagai berikut:

\section{Metode Observasi}

observasi yaitu metode pengumpulan data dengan cara mengadakan pengamatan dan pencatatan sistematis mengenai hal-hal penting terhadap obyek serta pengamatan terhadap masalah-masalah yang ada secara langsung. Dengan adanya survei lapangan didapat data-data yang sistematis melalui kontak langsung dengan masyarakat yang ada di sekitar tapak, yaitu dengan melakukan indentifikasi karakter-karakter masyarakat guna mengetahui terhadap bangunan. Pelaksanaan survei lapangan ini dilaksanakan secara langsung. Survei ini berfungsi untuk mendapatkan data berupa:

- Kondisi alam dan kondisi fisik kawasan perancangan

- Pengamatan aktivitas, dokumentasi gambar dengan menggunakan kamera. 


\section{Metode Dokumentasi}

Metode dokumentasi yaitu metode pengumpulan data dengan cara mengambil gambar dari obyek yang diteliti. Pengambilan gambar obyek dilakukan dengan menggunakan kamera atau dengan sketsa gambar. Metode ini dilakukan untuk memperkuat metode sebelumnya, yaitu metode observasi, agar lebih memperjelas datadata yang akan digunakan dalam analisis.

\section{Data Sekunder}

Yaitu data atau informasi yang berkaitan langsung dengan obyek perancangan tapi mendukung program perancangan, meliputi:

\section{Studi pustaka / Studi literatur}

Metode pustaka yaitu metode pengumpulan data dengan menggunakan atau mengambil dari buku-buku dan internet sebagai sumber bacaan dan referensi yang berkaitan dengan permasalahan yang dibahas. Data yang diperoleh dari studi pustaka ini, baik dari teori, pendapat ahli, serta peraturan dan kebijakan pemerintah menjadi dasar perencanaan sehingga dapat memperdalam analisa. Data yang diperoleh dari penelusuran literatur bersumber dari data internet, buku, majalah, brosur/pamflet, film dokumenter, dan aturan kebijakan pemerintah. Data ini meliputi:

- Data atau literatur tentang kawasan dan tapak yang terpilih berupa peta wilayah, peraturan pemerintah yaitu RDRTK Kota Jakarta. data ini selanjutnya digunakan untuk menganalisis kawasan tapak

- Literatur tentang proyek yang diambil, yaitu proyek tentang seni dan makanan

- Literatur mengenai tema utama yaitu "Third Place"

\section{Studi Preseden}

Metode ini dilakukan untuk mendapatkan data mengenai bangunan sejenis dan tema sejenis yang ada. Dalam pengumpulan data dan pengolahan data, data sekunder diperoleh tanpa pengamatan langsung tetapi menunjang proses kajian terhadap permasalahan. Data-data tersebut diolah dan dianalisa hingga diperoleh alternatif konsep. Pengumpulan data kondisi eksisting terhadap unsur-unsur yang ada di tapak, berikut interaksinya sehingga memunculkan masalah yang lebih spesifik. Evaluasi dilakukan melalui tahap informasi kondisi tapak, daya dukung tapak dan lingkungan berikut potensinya.

\section{Investigasi kawasan}

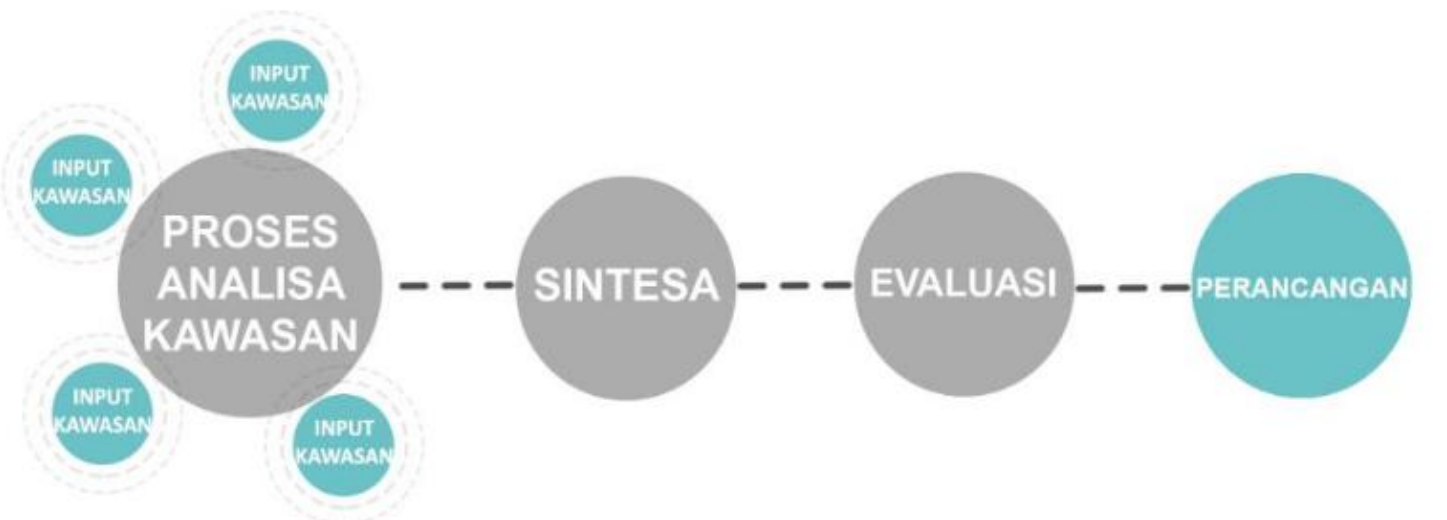

Gambar 8. Proses Analisa Kawasan

Sumber: Penulis, 2019

Tahap selanjutnya yaitu tahap analisis. Dalam proses analisis, dilakukan pendekatanpendekatan yang merupakan suatu tahapan kegiatan yang terdiri dari rangkaian telaah terhadap 
kondisi kawasan. Metode yang digunakan dalam analisis terdiri dari analisis makro, meso dan mikro. Analisis makro merupakan analisis dalam skala kawasan yaitu analisa kawasan. Sedangkan analisa mikro merupakan analisis terhadap tapak perencanaan, Untuk memunculkan nilai-nilai pada rancangan hasil dari analisis kawasan akan diubah yang menjadi sintesa yang akan dievaluasi sehingga memunculkan nilai-nilai perancangan yang akan dilakukan.

Data yang diperoleh selanjutnya dianalisis melalui pendekatan programatik perancanan, yaitu dengan menggunakan teori-teori perancangan arsitektur yang berkaitan dengan perancangan "Ruang Seni dan Kuliner Jalanan di Senen" serta nilai-nilai di atas sebagai dasar analisis yang akan diintegrasikan sebagai berikut.

\section{DISKUSI DAN HASIL}

Proyek ini dinamakan Ruang seni dan kuliner jalanan di senen dengan konsep dasar "Third place" yang berisi program yang mewadahi seni jalanan digabungkan dengan makanan dan minuman jalanan serta menjadikan bangunan ini berkontribusi positif terhadap kawasan.

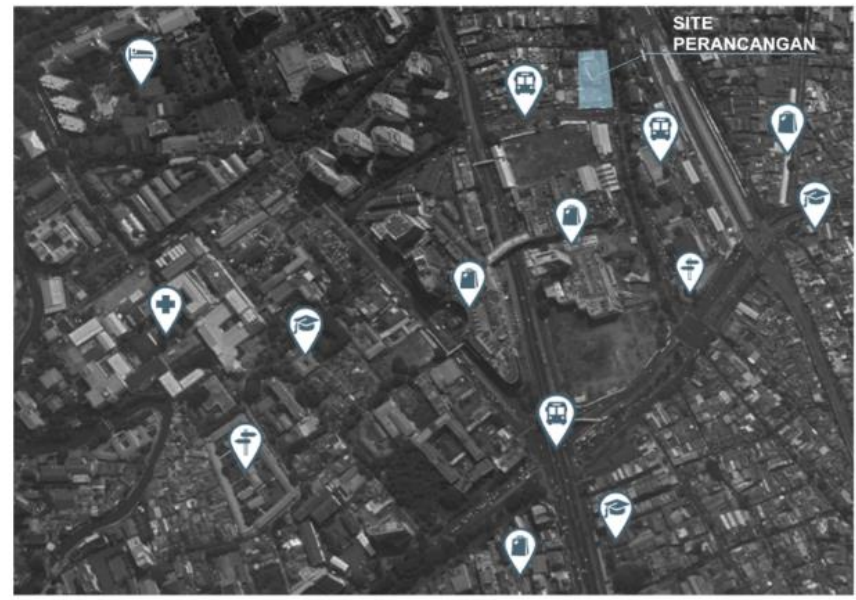

\section{FASILITAS PENUNJANG} TAPAK :

Kode kawasan :

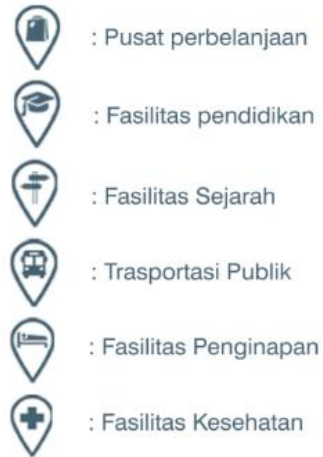

Gambar 9. Fasilitas Penunjang Kawasan

Sumber: Penulis, 2019

Lokasi tapak berada di Jl. Stasiun Senin bersebrangan dengan kawasan Stasiun Senen sehingga banyak ditemui para pengguna commuter yang didominasi pedestrian yang lalu lalang sekitar tapak membuat program makanan cocok dengan kawasan dan dari kawasan salah satu bentuk kontribusi tapak terhadap kota adalah dengan menjadikan sebagaian luas tapak linkage kota.Kawasan senen dahulu dikenal sebagai kawasan anak anak muda dengan adanya bioskop Grand dan seniman senen. Sehingga program kesenian dapat diulik sebagai program utama untuk mengembalikan citra kawasan senen.

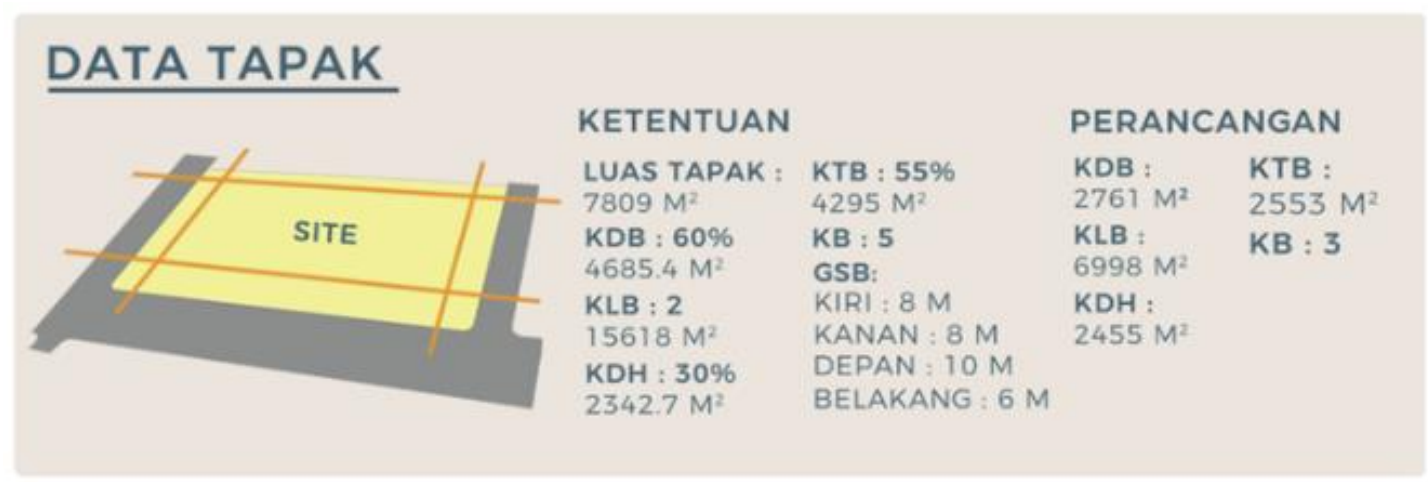

Gambar 10. Data Tapak

Sumber: Penulis, 2019 
Site memiliki peraturan pemerintah yaitu memiliki luas tapak $7809 \mathrm{~m}^{2}$ dengan besaran proyek sekitar maksimal $15618 \mathrm{~m}^{2}$ (KLB 2). Memiliki tinggi bangunan maksimal 5 lantai dengan peruntukan perdagangan dan jasa. Daerah hijau sebesar $2342.7 \mathrm{~m}^{2}(\mathrm{KDH} 30 \%)$, luasan dasar bangunan maksimal sebesar $4685 \mathrm{~m}^{2}$ (KDB 60\%) dan luasan basement maksimal sekitar 4295 $\mathrm{m}^{2}$ (KTB 55\%).

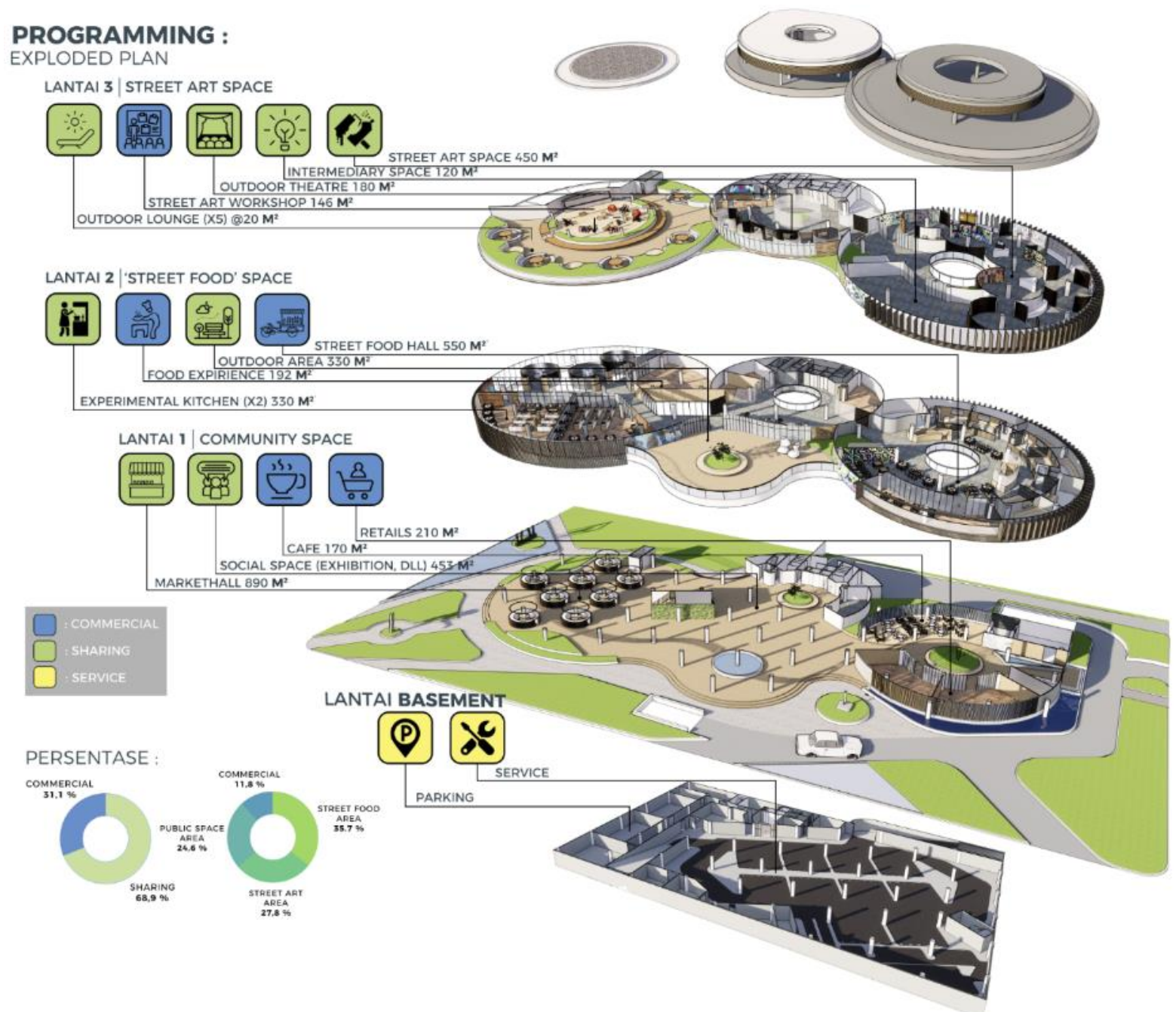

Gambar 11. Axonometri Program

Sumber: Penulis, 2019

Program utama pada proyek ini yaitu Markethall, Stree Art Space, Hawker Centre, Experimental Kitchen, Outdoor Theater, Food Expirience Merupakan program yang berkesinambungan dari kegiatan yang memberikan pengalaman kuliner dan seni yang dimulai dari melihat, mencoba, dan menjualnya

Setelah hubungan antara program ruang sudah didapatkan, maka proses selanjutnya adalah merancang gubahan massa. Massa dibagi menjadi tiga bagian dengan penyesuaian dengan kondisi site dan analisa program ruang. Berikut di bawah ini adalah diagram proses gubahan massa. 


\section{PROSES GUBAHAN MASSA}

STREET FOOD AND ART SPACE IN SENEN
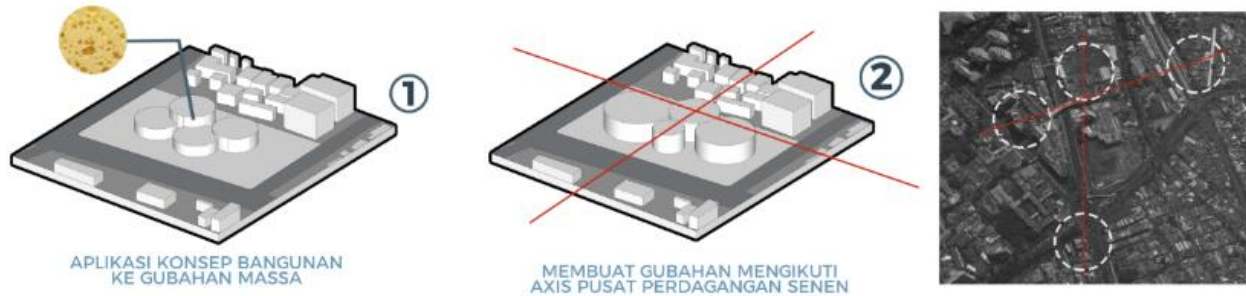

A: ATRIUM SENEN B: PASAR SENEN C: PASAR BUKU D: PASAR PONCOL
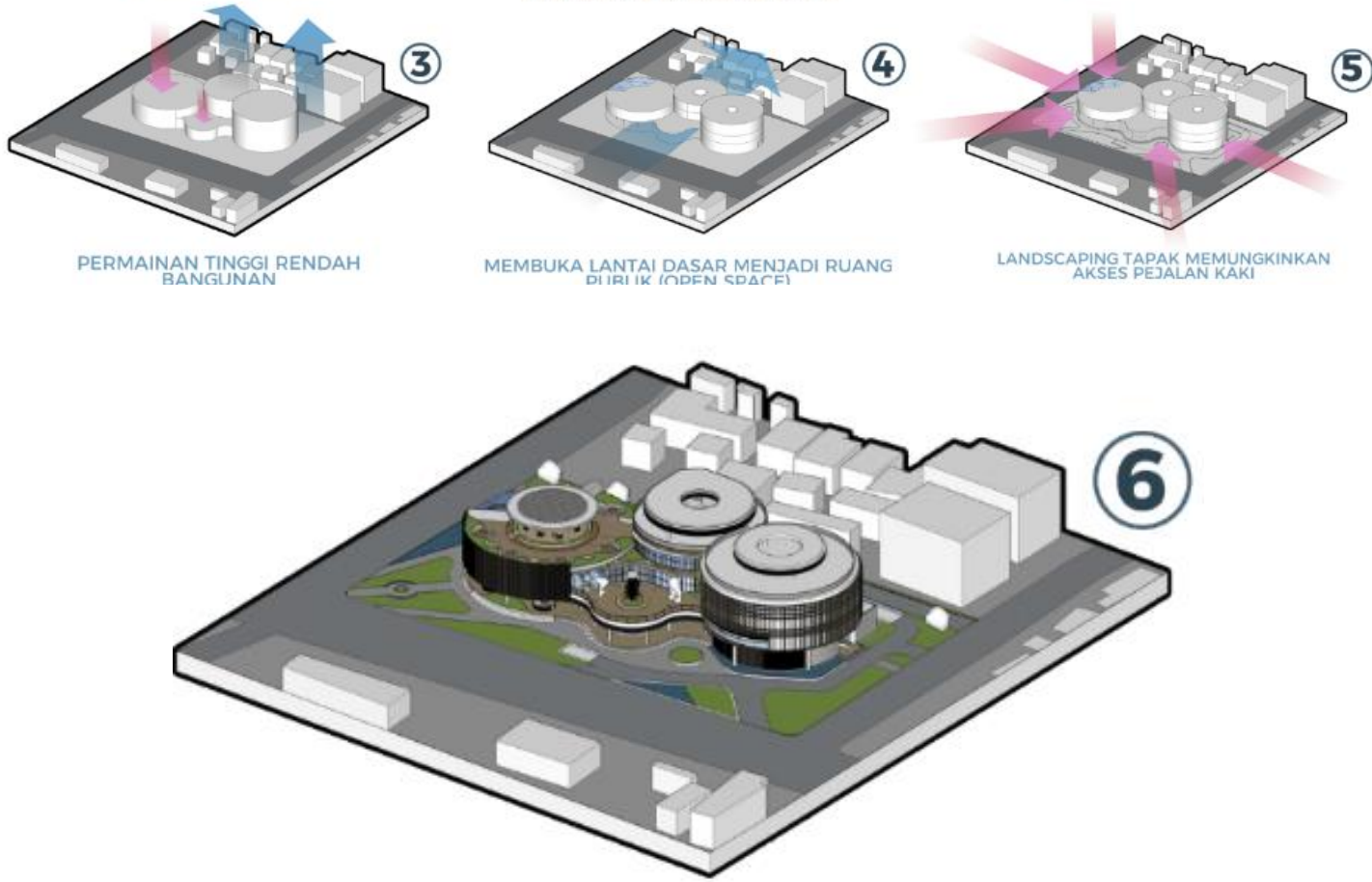

Gambar 12. Proses Gubahan Massa

Sumber : Penulis, 2019

Pengolahan gubahan massa bangunan didapat dari hasil analisa kawasan yang digabungkan oleh karakteristik kawasan dan konsep bangunan dari segi konsep massa bangunan dibuat lingkaran selain mengikuti konsep dari pori-pori spons, Dari segi konsep saya memilih agar bangunan dapat menjadi seperti sebuah spons. Mengambil sifat dari Spons proyek ini diharapkan dapat menyerap semua latar belakang dari masing-masing masyarakat dan seluruh latar belakang tersebut dapat melebur menjadi satu.bentuk massa bangunan dibuat semenerima mungkin dengan lantai dasar bangunan bersifat permeable (multi-akses) dengan bentuk lingkaran dapat mendukung sifat permeable.

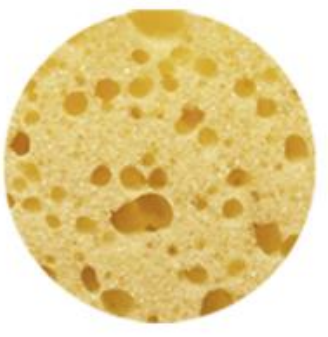

PORI-PORI SPONGE

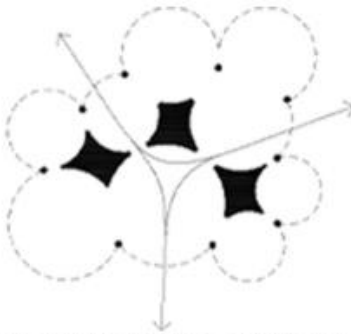

LANTAI DASAR BERSIFAT PERMEABLE (MULTI AKSES)

Gambar 13. Konsep dari Spons

Sumber: Penulis, 2019

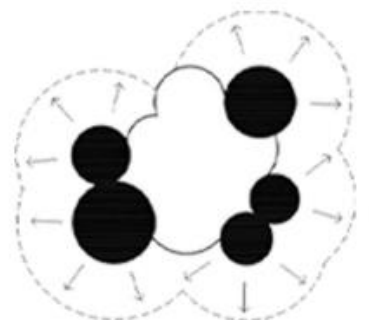

SETIAP "PORI PORI" MEMILIKI AKTIFITAS YANG MENGUNDANG 


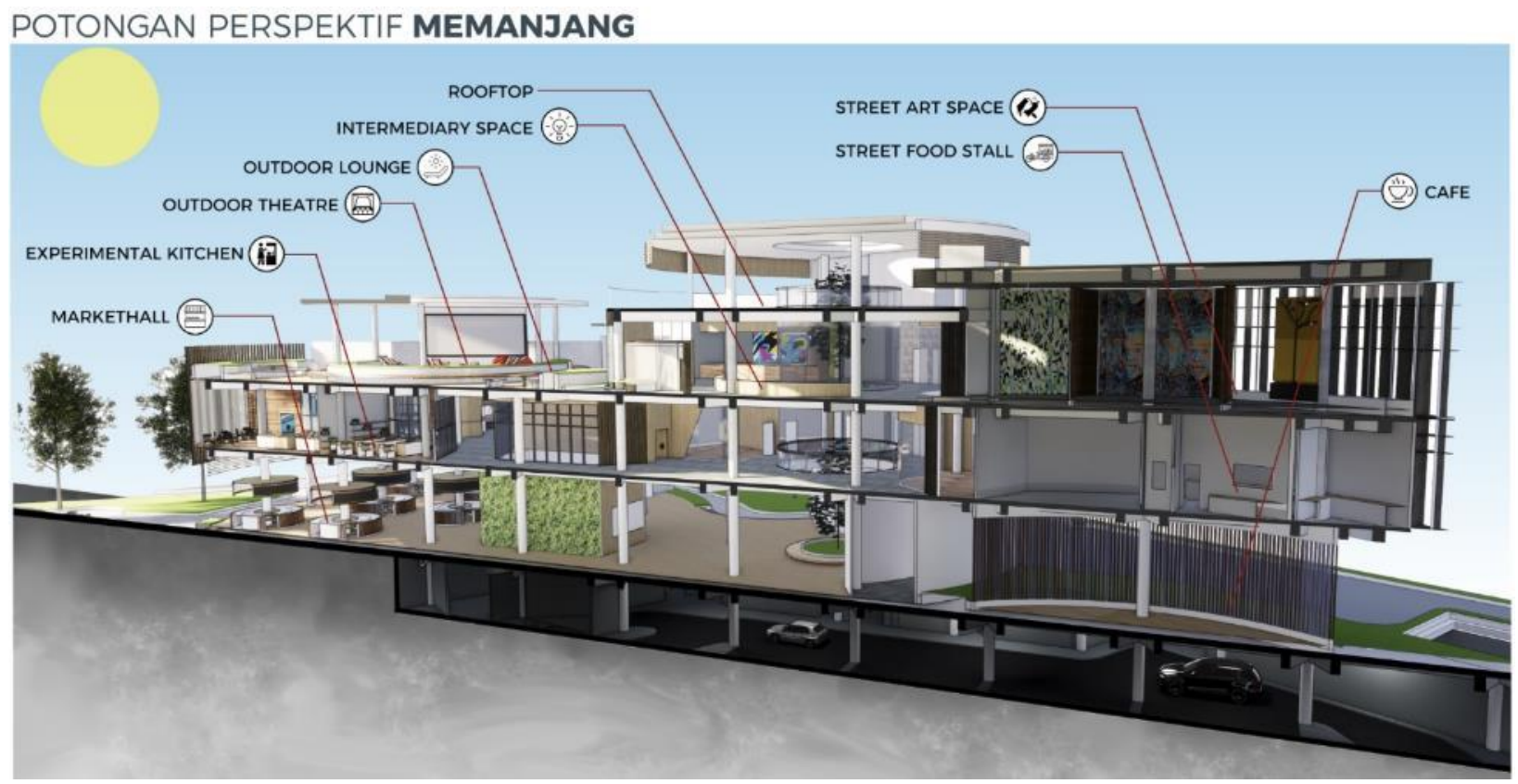

Gambar 14. Potongan Perspektif Memanjang bangunan

Sumber : Penulis, 2019

Pada gambar potongan perspektif diatas, dapat dilihat bahwa bangunan memiliki orientasi utama terhadap pedestrian sehingga main entrance utama di bagian depan khusus untuk pedestrian sedangkan drop-off kendaraan berada di belakang bangunan. Memisahkan sirkulasi pedestrian dan kendaraan agar tidak crossing. Lantai dasar bangunan dibuat seterbuka mungkin memungkinkan akses bebas oleh pedestrian, program pada lantai dasar juga disesuaikan dengan ciri khas dan kebutuhan dari Kawasan Senen.

\section{PERSPEKTIF INTERIOR}
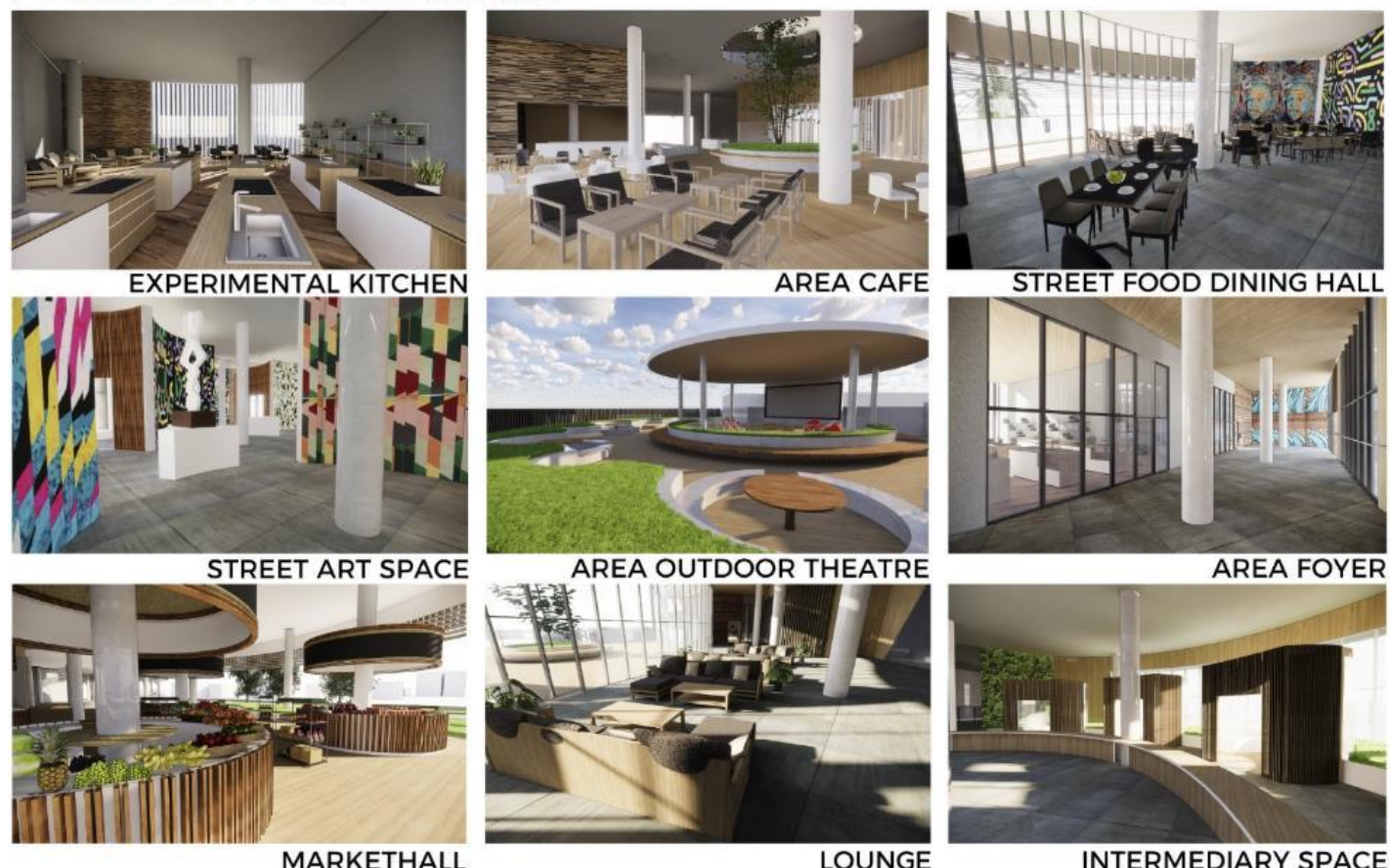

Gambar 15. Perspektif Interior

Sumber: Penulis, 2019 
Gambar diatas adalah gambaran suasana bangunan melalui perspektif interior pada siang hari di dalam tapak dapat digunakan sebagai linkage kota, disertai dengan food stands dan open space. Restaurant dan Café pada bangunan ini memanfaatkan suasana semi-outdoor dengan kesan homey sehingga masyarakat Kawasan Senen dapat beraktifitas pada bangunan ini.

\section{KESIMPULAN DAN SARAN}

Proyek yang akan diajukan dalam proposal ini yaitu "Ruang Seni dan Kuliner Jalanan di Senen" hal ini dikarnakan minimnya tempat publik yang layak dan mampu mewadahi kebutuhan masyarakat untuk berkesenian dan kegiatan yang merupakan bentuk dari interaksi sosial.Tema 'Street Food' dan 'Street Art' dipilih karena merepresentasikan kawasan proyek yaitu kawasan Senen Program "Street food and art Space" ini termasuk dalam kategori komersial, yang merupakan sebuah "Third place" untuk kawasan. Fasilitas utama pada program ini dibagi menjadi beberapa fungsi yang berkesinambungan yaitu: Street Art Space, Markethall, Hawker Centre, dan Experimental kitchen, dan Outdoor Theatre. Namun proyek ini masih belum dikatakan sempurna, Karena masih ada beberapa masukkan yang diberikan diantaranya lebih banyak meng-implementasikan konsep Sustainable pada bangunan ini agar lebih maksimal, Dapat menambahkan kapasitas ruang pada beberapa program utama agar dapat memaksimalkan kapasitas pengunjung yang datang, dan dapat menganalisis lebih dalam setiap tenant makanan yang akan dijual di bangunan ini agar beda dari yang lain dan sesuai dengan konsep perancangan.

\section{REFERENSI}

Appadurai, A. (1990). Disjuncture and Difference in the Global Cultural Economy. Theory Culture Society, DOI: $10.1177 / 026327690007002017$.

Carmona, M. (2003). Public Places- Urban Spaces, The Dimension of Urban Design..Diunduh 28 Agustus 2019, dari https://www.annualreviews.org/doi/full/ 10.1146/annurev.publhealth.29.020907.090926.

Carver, C. (2016, January 10). How street art can transform communities. Diunduh 28 Agustus, 2019, dari https://www.globalcitizen.org/en/content/how-street-art-can-transformcommunities/.

Florida, R. (2012). The Rise of The Creative Class, Revisited. New York: Basic Books.

Gastman, R., Neelon, C. \& Smyrski, A. (2007). Street World: Urban Art and Culture from Five Continents. New York: Harry N. Abrams.

Horwitz, J. \& Singley, P. (2004). Eating Architecture. Massachusetts: MIT Press.

Kaplan, D. M. (2012). The Philosophy of Food. California: University Of California Press.

Lidya. (2018, April 9). Street Food Sebagai Salah Satu Sisi Positif Bangsa Indonesia. Diunduh 23 Agustus, 2019, dari https://www.hujanpelangi.com/street-food-sebagai-salah-satu-sisipositif-bangsa-indonesia.html.

Musaba, M. (2015, February 10). Street Culture: An Emerging Underdog. Diunduh 28 Agustus, 2019, dari https://odyssey.antiochsb.edu/features/sb-local/street-culture-an-emergingmovement/.

Neill, A. (2008). Arguing about Art: Contemporary Philosophical Debates. London ; New York: Routledge.

Oldenburg, R. (1989). The Great Good Place: Cafes, coffee shops, bookstores, bars, hair salons and other hangouts at the heart of community. Philadelphia: Da Capo Press.

Project for Public Space. (2007). What is Placemaking? Diunduh 20 Agustus, 2019, dari https://www.pps.org/article/what-is-placemaking.

Tinker, Irene. (1997). Street Foods: Urban Food and Employment in Developing Countries. Oxford: Oxford University Press. 
